vidual letters of a word complex as the author and his subjects admit that they did, no one who has ever read proof can doubt, but this is surely not the same process as the normal reading of familiar words. But to establish the hypothesis of a roving attention in the apprehension of familiar word forms under really normal conditions of fixation during an exposure of . $I$ " one must fly in the face of the overwhelming evidence of the author's own experiments or espouse the hypothesis of unconscious changes in attention, which is about as good psychology as the hypothesis of unconscious ideas.

The author errs in concluding from a group of experiments in which the attention is directed toward the letters and letter groups that the same process occurs when the attention, is directed towards the sense.

Moreover, a movement of attention over the field of vision in reaction to the stimulus of unrecognized parts can certainly not occur during the time when the total stimulus has not yet overcome the inertia of the retina, $i . e$., within roo of the beginning of the exposure; that it might occur, according to Wundt's analysis in a somewhat shorter interval than the well-known Unterscheidungzeit is possible, but certainly not in less than one-third that interval, while the sharp fixation and total absence of the effort to let the attention wander which characterized the experiments of Erdmann and Dodge, must delay it still longer.

While the author's interpretation of his work in the form of Wundtian concepts is far from satisfactory, the experimentation itself is a valuable piece of work. Moreover, the emphasis laid on determining letter complexes which occur within the general word form is surely not altogether misplaced. The optical difference, however, between a group of letters and the same letters as constituent parts of a well-known word form seems to be as little appreciated as the psychological difference between the successive apprehension of the individual letters as such and the apprehension of that visual complex of contrasts which makes a word.

WESLEYAN UNIVERSITY.

Raymond Dodge.

\title{
A SCHEME OF CLASSIFICATION FOR PSYCHOLOGY.
}

The responsible editors of this REview drew up for the purposes of the Psychological INDEx the classification of psychological material which, with certain modifications suggested by the compiler of the Index, has been used heretofore in that publication. The coöperation effected with the German and French reviews emphasized the 
need of a common scheme, and Professor Warren represented the Review in a conference held in Paris during the recent International Congress. The agreements reached, together with certain alterations made subsequently suggested are now embodied in the following scheme. It is thought that this scheme-having thus the authority of an international committee and embodying the opinions of experienced bibliographers of psychology-may have value for the wider use of public and private libraries, and we recommend it to all those who are interested in psychological classification. That it avoids all difficulties and inconsistencies we do not pretend to say; it embodies compromises and considerations of utility as well as those of logic.

In the division headings two alternative schemes are presented: the 'graded numerals' and the 'decimal system.' The INDFx continues to use the former; but others who wish to adopt the classification may prefer to use the decinal systcm.

J. Mark Baldwin.

\section{CLASSIFICATION.'}

o. I. General :

o.I I. Text-books and Systematic Treatises.

$0.2-05$ 2. General Problems, Methods, Terms and Apparatus.

0.6 3. History and Biography.

0.7

4. Collections, Proceedings, Dictionaries, Bibliographies.

1.

1.0

1.1

1.2

1.21

1.22

1.3

II. Anatomy and Physiology of the Nerrous System.

I. General.

2. Nerve Eltments.

3. Brain and its Functions.

a. Anatomy of the Brain.

b. Physiology of the Brain.

4. Spinal Cord, Nerves and Sympathetuc System.

5. Reflex and Automatic Functions.

6. Pathological Anatomy.

2.0 I. General.

2 2. Sense Organs (General).

3. Psycho-physics (Weber's Law, etc.).

4. Psychometry. (See Time Relations, IV7.)

5. Vision :

a. General.

b. Anatomy and General Physiology of the Eye.

IIn the matter of English terminology the recommendations of Baldwin's Dict. of Philos. and Psychol, now in the press of the Macmillans, are anticipated and followed by permission (with view also to the German, French, and Italian equivalents given in that work). 
6.

6.0

6.1

$6.2-6.4$

6.5

6.51

6.52

c Physics and Special Physiology (Dioptrics, Refraction, Accommodation, Acuteness of Vision, Perimetry, etc.). d. Visual Sensations.

$e$. Special Phenomena of Vision (After-images, Contrast, etc.).

f. Eye Movements and Binocular Vision.

6. Hearing:

g. Pathology.

a. General.

b. Anatomy of the Ear.

c. Physics and Physiology.

d. Auditory Sensations.

e. Pathology.

7. Other Senses:

a. Taste.

b. Smell.

c. Cutaneous, Pressure and Joint Senses.

d. Muscle sense.

e. Static Senses (Position, Equilibrium, and Dizziness).

$f$. Organic, Pleasure and Pain Senses; General Sensibility.

g. Electric Sense.

8. General Pathology.

IV General Characters of Consciousness:

I. General.

2. Attention and Apperception.

3. Association.

4. Dispositions

5. Habit, Accommodation, and Selection.

6 Work and Fatigue.

7 Time Relations; Mental Chronometry.

v. Cognition:

I. General.

2. Perception and Idea

3. Perception of Time, Space, and Motion.

4. Memory and Imagination. (See also Dreams, IXI.)

5. Judgment and Belief; Reasoning.

6. Reflection and Self-consciousness.

7. Normal Illusions and Suggestion.

8. General Pathology.

VI. Affection (Feeling and Emotion):

I. General; Pleasantness and Unpleasantness.

2. Emotion and its Expression.

3. General Pathology.

VII. Conation and Movement :

I. General; Dynamogenesis.

2. Organs of Movement. (See Muscle Sense, III $7 d$.)

3. Instinct and Impulse (Imitation, Play, etc.).

4. Special Motor Functions :

\section{a. Speech}

$b$ Handwriting. 


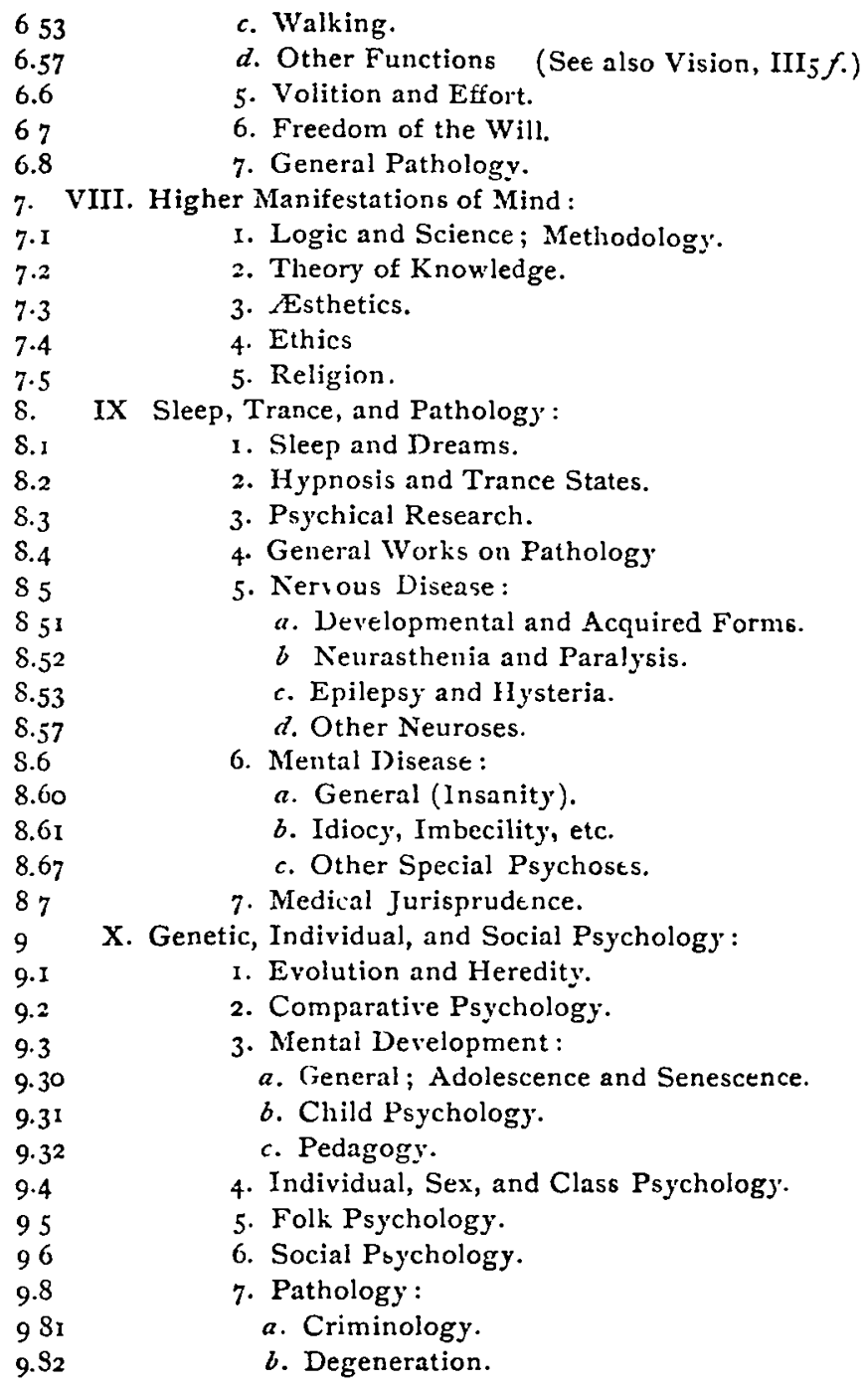

\section{A DISCLAIMER.}

The attention of the undersigned has been called to the fact that an organization known as 'The American College of Sciences,' situated in Philadelphia, is issuing circulars advertising a course of instruction in hypnotism as prepared in part by them. These circulars contain many statements about hypnotism and about the advantages to be derived from its study and practice which are not justified by the 